\title{
DEVIR E ESCRITA NA FILOSOFIA DE DELEUZE E GUATTARI
}

\section{ARTIGO ORIGINAL}

SANTOS, Géssica Brito ${ }^{1}$

SANTOS, Géssica Brito. Devir e escrita na filosofia de Deleuze e Guattari. Revista Científica Multidisciplinar Núcleo do Conhecimento. Ano 06, Ed. 01, Vol. 06, pp. 96110. Janeiro de 2021. ISSN: 2448-0959, Link de acesso: https://www.nucleodoconhecimento.com.br/letras/devir-e-escrita

\section{RESUMO}

A escrita é sempre inacabada por estar sempre produzindo novas relações de multiplicidades e por ser detentora de um enunciado que fala por si. Ela é impessoal por ter a capacidade de criar artifícios para se conjugar novos enunciados, cujo centro não é o indivíduo, mas, todas as relações de agenciamentos que existem em torno dele e de outros agentes, relações homem e natureza, homem e tempo, homem e objeto. Essa é a ideia de desterritorialização da escrita definida pelos filósofos franceses Gilles Deleuze (1925-1995) e Félix Guattari (1930-1992). O presente artigo tem como objetivo indagar em que medida a escrita literária pode ser compreendida como um caso de devir. Em cotejo à análise do conceito de devir e em como a literatura é atravessada por esse pensamento filosófico, iremos discutir a obra Moby Dick (1851) do escritor estadunidense Herman Melville (1819-1891), exemplo amplamente utilizado pelos próprios autores em livros como Mil Platôs - Devir-intenso, Devir-animal, Devir-imperceptível (2012) e Crítica e Clínica (2011). O artigo parte de uma investigação de cunho bibliográfico e se apoia no estruturalismo como recurso metodológico.

Palavras-chave: Devir, literatura, agenciamento, desterritorialização.

\footnotetext{
${ }^{1}$ Graduada em Letras pela Universidade do Estado da Bahia.
} 


\section{INTRODUÇÃO}

O conceito de devir ganhou forma quando Gilles Deleuze conheceu, em 1968, seu amigo Félix Guattari, e os dois se propuseram a criar uma prolífica parceria. Juntos, escreveram quatro livros, O Anti-Édipo (1972), Kafka. Por uma literatura menor (1975), Mil Platôs (1980) e O que é a filosofia? (1991). Assim, dessa parceria surgiu uma nova maneira de se pensar o indivíduo e sua relação com a natureza.[2]

A visão antropológica do conceito de devir defendida por Deleuze e Guattari, que permite a aproximação das origens da natureza humana e de suas relações com a natureza animal, é tomada como formulação para compreender esse conceito como crucial à outras áreas de saber, uma vez que o devir procura explicar as relações humanas. O elemento que mais parece se aproximar da compreensão do homem e do mundo é a linguagem. Assim, pensar em devir significa pensar em linguagem.

No tocante à escrita ficcional, o devir se traduz como ruptura e povoamento. Atribuídos a isso, se observa uma série de aspectos que envolvem relação obra e autor, produção e agenciamento. A obra é tida como um mapa cartográfico, atravessada por uma infinidade de afectos e agenciamentos. O autor, por sua vez, é produto desse agenciamento e trata de conduzir sua obra de maneira impessoal, adotando uma linguagem enunciativa, coletiva e desterritorializada, em que se tolera a invenção de relações múltiplas. As seções do presente artigo se ocupam dessa discussão.

\section{O CONCEITO DE DEVIR: PACTO, DESTERRITORIALIZAÇÃO E AGENCIAMENTO}

$\mathrm{Na}$ literatura o devir pode ser compreendido de várias maneiras. A partir da experimentação da linguagem, o devir-outro da língua, a criação de uma língua estrangeira, a partir do estilo do escritor e da fabulação. No entanto, todos esses elementos culminam num único propósito, a desterritorialização da escrita. "Escrever é um caso de devir" (DELEUZE, 2011, p. 11), porque a escrita é território para o autor produzir novas alianças e enunciados. 
Em Mil Platôs - Devir-intenso, Devir-animal, Devir-imperceptível (2012)[3], Gilles Deleuze e Félix Guattari ilustram a questão, tomando como exemplo o livro Moby Dick[4], de Herman Melville. Capitão Ahab, o protagonista do livro, e Moby Dick, um cachalote que se distingue dos demais por características incomuns a um animal, mantêm uma fronteira de vizinhança, que desterritorializa, tanto o homem quanto a baleia. Ou seja, eles saem do ambiente comum: o cachalote de sua natureza animal e Capitão Ahab da sua natureza humana. A desterritorialização, para os autores, é responsável pelo devir-baleia de Ahab e o devir-homem de Moby Dick.

Deleuze e Guattari (2012) sinalizam que a linha de fuga pode ser compreendida como uma maneira que os agentes têm de dissociar-se do que são, e encaminharem-se para uma nova criação, mas que não é conclusiva já que devir é movimento, nada é definitivo. A propagação é uma transmissão e uma forma de povoar as coisas com novas relações. Encontra-se aí uma concepção perfeita para como surge o devir, por transmissão ou povoamento, e não por algo que se filia ou repete.

Moby Dick tem uma anomalia que o faz diferenciar-se das demais baleias e permite também que ele seja afetado pelas potências de um devir-homem. Capitão Ahab a escolhe para um pacto subversivo e sela com a baleia uma estranha atração "não humana", uma relação de simbiose. O contato com a baleia permite a Ahab estabelecer um afecto que desorganiza toda a hierarquia padrão que se tem da relação indivíduo e natureza.

É dessa capacidade de irregularidade e fuga que o devir na escrita ocorre. O devir se origina da potência de agentes que por alguma causa saem de um agenciamento, entrando em desterritorializações ou em linhas de fuga. $O$ devir dependerá da postura desse agente, dessa máquina em potencializar uma ruptura contra os agenciamentos de poder. Em Moby Dick essa irregularidade pode ser notada a partir dos elementos da escrita, como a fabulação e o estilo do escritor. Assim, o enunciado literário converge para o que há de inovador na literatura e para aquilo que, de algum modo, repercutirá na linguagem coletiva. Quando Deleuze e Guattari falam em "invenção de um povo que falta", falam em enunciações que se produzam na literatura, e saem dela servindo como uma nova forma de expressão, do que dizer e do que pensar. 
No livro, o personagem Ahab abre espaço para o "preferido", o anômalo. "[...] o capitão Ahab tem um devir-baleia irresistível, mas que justamente contorna a matilha ou o cardume, e passa diretamente por uma aliança monstruosa com o Único, com o Leviatã, Moby Dick." (DELEUZE; GUATTARI, 2012, p. 21)

O personagem sente atração pela "coisa". Isso significa que a atração de Capitão Ahab não leva em conta só a baleia, mas as potências que partem dessa relação. Por isso, devemos pensar que houve uma atração por contágio entre baleia e homem, agentes bem distintos.

O termo anômalo para Deleuze e Guattari é definido como uma "coisa", sentido figurado de algo que não se pode definir, justamente, por causa de sua indiscernibilidade. Então, pode-se dizer que o devir é povoado por esses agentes estrangeiros que fazem parte de um grupo, ou matilha, e que se destacam por conseguirem traçar curvas e fissuras em seus grupos.

Segundo Deleuze e Guattari:

[..] qual é a natureza do anômalo, ao certo? Que função ele tem em relação ao bando, à matilha? É evidente que o anômalo não é simplesmente um indivíduo excepcional, o que o remeteria ao animal familial ou familiar, edipianizado à maneira da psicanálise, a imagem de pai..., etc. Para Ahab, Moby Dick não é como o gatinho ou o cachorrinho de uma velha que o cobre de atenções e o paparica. (DELEUZE; GUATTARI, 2012, p. 22)

Neste trecho, Deleuze e Guattari se atentam para aquilo que foge à ideia de filiação. Há devir na relação baleia e homem porque essa relação não é determinada pela semelhança entre os agentes. Os autores chamam a atenção para o fato da domesticação caracterizar-se como uma imitação que o animal faz do homem quando convive de modo amigável com ele. A baleia não é um animal domesticado, por isso, tem a capacidade de emitir todas as potências do animal.

Ora, "a escrita está por essência no ato de ruptura, no devir outro que pode ser o devirmulher, o devir-animal ou vegetal, mas que é em qualquer hipótese um devirminoritário, de simples vizinhança [...]" (DOSSE, 2010, p. 354). Pode-se dizer que em 
Moby Dick, a baleia branca entra numa zona de vizinhança com o Capitão Ahab. Isso porque, ela capta intensidades que vem do homem e passa por um fenômeno de borda quando demonstra características humanas. Moby Dick assume características humanas, ao expressar raiva, sentimento de vingança, rancor pelos baleeiros e por Ahab. O sentimento de fúria de maneira lúcida e calculada do cachalote sinaliza uma desterritorialização. Por sua vez, o Capitão Ahab é um homem frio que nutre uma obsessão pela baleia Moby Dick e que passa todo o tempo dedicado a arquitetar meios de capturar o mamífero. A baleia, anômala, inteligente e vingativa, inicia o pacto com Capitão Ahab, passando por um devir-homem. Deleuze e Guattari observam que não cabe na narração uma imitação entre baleia e homem.

Percebe-se que a obra Moby Dick serve de referência para Deleuze e Guattari elucidarem o processo de criação ficcional e todas as formas de agenciamento e potência do autor em contato com seu texto. Tendo em vista a perspectiva levantada pelos autores, a produção literária de Herman Melville formula-se como portadora de uma linguagem desterritorializante, para o qual, converge-se singularidade (ruptura, delírio e estilo do escritor), e a busca de novos enunciados (fabulação e potência criadora).

Desse modo, a obra ficcional, quer seja na produção das novas relações percebidas dentro da ficção e a capacidade inventiva da língua pelo autor, quer seja o diálogo político que ela possa assumir em seu exterior, se condiciona à um conceito base, a escrita se faz terreno para novos povoamentos. Escrever de modo que não seja apenas a sua história de vida, do "autor absorto em suas mistificações sonhadoras, mas a de nos fazer sentir a aproximação de uma estranha potência, neutra e impessoal." (BLANCHOT, 2005, p. 139).

O que se percebe em uma escrita menor, aquela que é atravessada pelo devir, é que personagens, narrador e escritor são posições, são máquinas que representam um coletivo. Não dá para pensar no nome do personagem sem pensar no agenciamento que ele representa. Birman (2000) ao comentar o conceito de devir em Deleuze e Guattari recorda que: 
A literatura é habitada por fluxos, intensidades e afecções que transformam a língua familiar em língua estrangeira. Assim, o sujeito só se deixará apreender como tal desprendido e liberado do registro da pessoalidade do Eu. (BIRMAN, 2000, p. 477)

Birman afirma que, quando se "inventa um povo" ou quando se fala em língua estrangeira, expressões utilizadas por Deleuze e Guattari para explicarem o processo de criação do autor, é quando desponta-se uma visão coletiva, no qual, o enunciado produzido pela literatura, o de falar de todos e de tudo destituído do si, parece ter um lugar mais preponderante. Por isso, escrever seria passar por intensidades de potências forçando a linguagem, tomada de conteúdo e expressão, a ir à um outro nível da linguagem que não a comum. Segundo Birman (2000, p. 477):

A fabulação seria, pois, a própria potência em ato, que traduziria a língua instituída como estrangeira. Assim, a escrita supõe não apenas a decomposição da língua materna, mas também "a invenção de uma nova língua dentro da língua, pela emoção da sintaxe".

$\mathrm{Na}$ literatura menor o estilo é sempre político, como que comandado por um desejo revolucionário que parte de todas as máquinas que fazem parte do agenciamento enunciativo. Por este motivo é que Deleuze e Guattari (2002) enxergam o escritor também como parte dessa máquina:

Um escritor não é um homem escritor, é um homem político, um homem máquina, e também é um homem experimental (que, deste modo, deixa de ser homem para devir macaco, ou coleóptero, cão, rato, devir animal, devir inumano, porque, na verdade, é pela voz, é pelo som, é através de um estilo que se devém animal, e, seguramente, à força de sobriedade). (DELEUZE; GUATTARI, 2002, p. 26)

A observação de Deleuze e Guattari é a de que o escritor acaba produzindo agenciamentos coletivos na literatura por ele próprio ser produto de um ou mais agenciamentos. Os agenciamentos são sempre coletivos, como lembra o autor em Diálogos (1998), pois formam grupos, multiplicidades. A cada obra escrita, o escritor entra numa linha de fuga, que permite que ele esqueça tudo que foi, esqueça as lembranças, e torne-se aquilo que escreve, torne sua escrita distante de si, e próxima a uma ideia coletiva. 
Dessa maneira, o autor é traduzido como uma máquina, movido por uma potência que é impessoal e que tem um agenciamento enunciativo que não pode ser outra coisa senão coletivo. Durante a criação literária, o artista passa por esse momento de intensidade, e o que se ver na obra é a reunião de devires, de singularidades e de potencialidades, como a fuga de devir-baleia de Ahab em Moby Dick, força "irresistível" explicada da aliança do homem com a baleia. Tal narrativa é carregada de uma potência, que envolve a forma como acreditamos no que é contado.

\section{O DEVIR-MENOR DA LÍNGUA}

A literatura para Deleuze e Guattari é atravessada por um devir-menor da língua que permite ao escritor criar um estilo, uma língua estrangeira que se caracteriza pelas brechas que se pode abrir na linguagem. $O$ escritor tem a capacidade de abrir rupturas na produção literária, de inventar uma língua estrangeira, "estar na sua própria língua como um estrangeiro." (DELEUZE; GUATTARI, 2002, p. 54). Isso envolve criar sua própria forma "agramatical".

Uma língua é atravessada por linhas de fuga que conduzem seu vocabulário e sua sintaxe. E a abundância do vocabulário, a riqueza da sintaxe são apenas meios a serviço de uma linha que se julga, ao contrário, por sua sobriedade, sua concisão, sua abstração: uma linha involutiva não apoiada que determina os meandros de uma frase ou de um texto, que atravessa todas as redundâncias e rompe as figuras de estilo. É a linha pragmática, de gravidade ou de celeridade, cuja pobreza ideal comanda a riqueza das outras. (DELEUZE; PARNET. 1998, p. 136)

Neste trecho, Claire Parnet e Deleuze destacam a sintaxe como forma de explicar o desvio daquilo que é padrão na escrita. Escrever em língua estrangeira como um devir-menor da língua não implica na saída de uma língua materna à outra, mas sim, uma língua menor, desterritorializada e inscrita na língua materna. De acordo com Parnet e Deleuze (1998), a ruptura na literatura consiste numa linha de fuga que faz com o escritor rompa com os padrões de linguagem e escrita e crie sua própria forma de escrever.

O escritor faz isso, muitas vezes, como para explorar um paradoxo por uma "fórmula agramatical"[5]. Um exemplo claro de desvio na língua que culmina com a criação de 
uma língua estrangeira se encontra na obra Bartleby, o Escriturário (1853), novela de Herman Melville. O personagem que dá nome ao título do livro, tem um comportamento bem peculiar ao desafiar o patrão e a todos somente com a frase $I$ would prefer not to[6]. Deleuze observa que:

A fórmula comum seria antes I had rather not. Mas sobretudo a extravagância da fórmula extrapola a palavra em si: sem dúvida, ela é gramaticalmente correta, sintaticamente correta, mas seu término abrupto, NOT TO, que deixa indeterminado o que ela rechaça, the confere um caráter radical, uma espécie de função-limite. (DELEUZE, 2011, p. 91)

Deleuze acredita haver uma "agramaticalidade" nessa frase, um desvio, pois, a frase em inglês, desobedece a ordem de sentido padrão da língua que a coloca como um caso especial. Como ele destaca, enxerga-se na frase uma função-limite usada pelo personagem para aprovar ou negar qualquer coisa a partir dela. Seu sentido vai depender do uso que o personagem faz. O devir é essa nova investida na língua, a língua estrangeira, de modo que a leve a uma escrita menor.

Em Moby Dick o desvio da língua é notado na anomalia da baleia, no outsider. "Melville inventa uma língua estrangeira que corre sob o inglês e que o arrasta: é o OUTLANDISH, ou o Desterritorializado, a língua da Baleia." (DELEUZE, 2011, p. 95).

Segundo Dosse "a língua menor é definida, portanto, por seu hibridismo no interior mesmo da língua maior" (DOSSE, 2010, p. 204). Assim, na escrita a enunciação é um devir composto de intensidades que leva uma língua maior a abrigar uma língua menor, esta língua menor, no entanto, não significa outra língua em termos de tradução, mas uma nova forma de escrever de modo que não seja por um modelo, de romper em sintaxe com a língua padrão, formando uma agramaticalidade, com muitos desvios, dando a composição literária um estado de fuga. Sobre isso Machado (2009) pontua:

Fundamentalmente, o que interessa a Deleuze na questão da linguagem literária é o estilo como uma nova sintaxe que possibilita que o escritor produza um devir-outro da língua, um "delírio" que a faz sair dos eixos, dos trilhos, que a faz escapar do sistema dominante. Assim, ele privilegia na literatura o modo como o escritor decompõe, desarticula, desorganiza 
sua língua materna para inventar uma nova língua, uma língua marcada por um processo de desterritorialização. Como? Não pela mistura de línguas diferentes, mas por meio de uma construção sintática, da criação de novas potências sintáticas, gramaticais - seria ainda melhor dizer assintáticas, agramaticais - que lhe dê um uso intensivo, oposto ao uso significativo ou significante. (MACHADO, 2009, p. 207)

Percebe-se que o devir menor da língua é capaz de criar uma intensidade que não permanece somente na sintaxe da linguagem. Chama à atenção o fato de potências da linguagem fazerem conexão com um fora. Nem interior e nem exterior, para Deluze e Guattari (2012) a literatura é essa potência nela mesma que ultrapassa essas duas zonas.

Para Ovídio Abreu (2006) a literatura menor defendida por Deleuze e Guattari vai além de uma criação sintática da linguagem. É uma definição que oferece um significado que envolve um fora, envolve toda uma cadeia de agenciamentos de expressão enunciativa e todo regime de signo implícito que faz com que a escrita seja política e entre também em um devir-revolucionário:

O conceito de literatura menor tem os seguintes componentes: a potência da desterritorialização da língua que permite uma criação de uma língua estrangeira na própria língua materna; a conexão imediata do individual com o político, que passa por relações complexas com a experiência de minorias; e o já mencionado agenciamento coletivo de enunciação. Além disso, a literatura menor é inseparável de um tratamento menor da língua. Mas nada disso se conquista sem um tratamento sintático sempre renovado: a literatura é, para Deleuze, sintaxe conduzida a um limite agramatical para revelar a vida nas coisas. (ABREU, 2006, p. 204)

A sintaxe da literatura menor é aquela cujo desvio vem de um estilo do escritor em criar uma gagueira na linguagem. Não é gagueira da fala, não é erro, é empregar um desvio que faz a língua sair do padrão, e ir para um fora. É conseguir arrancar de um desvio agramatical na escrita um contexto que vai além do que está escrito, e que rompe da linguagem o que é indizível e a leva a sensação de estrangeiro.

Essa ruptura agramatical da língua pela literatura menor é uma espécie de delírio. Para escrever em outra língua, para desviar a sintaxe de modo que dela se alcance 
um contexto político na linguagem, faz-se necessário esse delírio. O delírio é o devir, é a criação de um estilo.

Deleuze e Guattari (2012) diz que o escritor leva a linguagem ao extremo ${ }^{[7]}$ por causa da presença de um impessoal. O impessoal acaba desconfigurando a linguagem ao encontrar nos artigos indefinidos, um lugar de origem para termos individuados que não representam o pessoal, mas, agentes que exercem funções em agenciamentos. Nesse sentido, Deleuze e Guattari expõem o que é o ato de criação literária, se pensada como impessoal:

Então se é como o capim: se fez do mundo, de todo mundo, um devir, porque se fez um mundo necessariamente comunicante, porque se suprimiu de si tudo o que impedia de deslizar entre as coisas, de irromper no meio das coisas. Combinou-se o "tudo", o artigo indefinido, o infinitivodevir e o nome próprio ao qual se está reduzido. Saturar, eliminar, colocar tudo. (DELEUZE; GUATTARI, 2012, p. 64)

Eles apontam que a atividade de escritor é coletiva; personagem é destituído de sujeito para assumir uma função, ser visto como função para seu grupo ou matilha. $O$ próprio escritor também é função, como observamos no trecho. O escritor é responsável por seu povo, por levar a escrita aos limites ao escrever "por" e "para" agentes individuados, escrever sobre tudo e ter a obra destituída da sua pessoa, não transformar o texto em suas próprias lembranças. Ora, é verdade que o escritor é atravessado por influências na produção literária, mas a obra criada não mais o pertence, pertence a um olho exterior. A obra, nessa perspectiva é impessoal.

O escritor é agenciado, produz uma literatura que é fruto de agenciamentos. Tudo que escreve passa pelos afectos que ele recebe, fazendo com que ele produza uma escrita impessoal e coletiva. Assim, a escrita impessoal remete ao que é indefinido, não é o eu, porque não existe o sujeito. Não se trata então de "eu morro", mas de "morre-se" (DELEUZE; PARNET, 1998, p. 77). Não é preciso ser uma criança para escrever sobre uma, aqui é onde a impessoalidade da escrita funciona.

Deleuze aponta que a escrita é impessoal porque não é uma história privada, mas, agenciamento coletivo. 
A literatura só se afirma descobrindo sob as pessoas aparentes a força de um impessoal que não é de modo algum uma generalidade, mas uma singularidade no mais alto grau: um homem, uma mulher, um animal, um ventre, uma criança... As duas primeiras pessoas do singular não servem de condição à enunciação literária; a literatura só começa quando nasce em nós uma terceira pessoa que nos destitui do poder de dizer Eu (o "neutro" de Blanchot). (DELEUZE, 2011, p. 13)

Acerca desse impessoal, deve-se notar que, no francês, há a partícula "on", que é um pronome pessoal. Ele é intraduzível. Geralmente, vemos, por exemplo, na conjugação do verbo parler (falar) junto com o "on", "on parle" por "fala-se", ou "se fala", às vezes ele parece adquirir a função do nosso "a gente". No caso do [IL, "ele" em francês] Deleuze chama atenção ao fato de, na língua francesa o pronome aparecer em ocasiões como "ll pleuf", que quer dizer "Chove!" (em português é uma oração sem sujeito, que é gramaticalmente inadmissível em francês). Em casos como o que foi citado, a partícula "il" não designa propriamente uma pessoa, um sujeito ou uma personificação. Como escreve no trecho, em termos de linguagem, as duas primeiras pessoas (eu; tu) são subjetivadas porque remetem a um eu. A função desempenhada pela terceira pessoa não é exatamente a mesma na gramática de língua francesa e na de língua portuguesa.

Deleuze e Guattari (2012) analisam a agramaticalidade de algumas palavras em francês para provar como a linguagem converge para uma ruptura, de modo que possa ela ser considerada impessoal, porque se torna indefinida, sem sujeito. O "on" da língua francesa é impessoal, não indica uma subjetivação. Quando invocamos o "il", perde-se a conexão com um possível sujeito, uma vez que, no enunciado, não há interiorização por parte desse pronome intraduzível, diferente das duas primeiras pessoas, como mostram Deleuze e Guattari (2012):

O IL não representa um sujeito, mas diagramatiza um agenciamento. Ele não sobrecodifica os enunciados, não os transcende como as duas primeiras pessoas, mas, ao contrário, os impede de cair sob a tirania das constelações significantes ou subjetivas, sob o regime das redundâncias vazias. As cadeias de expressão que ele articula são aquelas cujos conteúdos podem ser agenciados em função de um máximo de ocorrências e devires. (DELEUZE; GUATTARI, 2012, p. 46) 
Os autores indicam que da própria sintaxe da linguagem surge um desvio que desencadeia a um impessoal literário. $O$ "on" é pura singularidade, porque não se subjetiva. O pronome intraduzível pode surgir como possibilidade de, no ato da criação literária, levar a escrita a novas experiências da linguagem impessoal.

René Schérer em Homo tantum. O impessoal: uma política, comenta que o impessoal da estrutura linguística configurado no artigo indefinido e pronome, leva a linguagem a se distanciar da ideia de corpo subjetivado e mergulha na ideia da individuação quando define que "essa camada do meio, esse 'entre', entre as palavras e as coisas, esse 'neutro', sentido expresso ou noemático, é o lugar do impessoal ou o plano que o impessoal desdobra". (SCHÉRER, 2000, p. 27), porque é onde a singularidade impõe à linguagem um limite e institui um agenciamento na qual o "um", representa um múltiplo, porque se dirige a um agente que é determinado, mas indefinido porque é visto como função e não como sujeito. Desse modo, a singularidade na escrita é essa ausência de sujeito que em nada compromete a linguagem porque dela surgem agentes indefinidos "um" e "ele" [il; on], e esses agentes só são reconhecidos a partir de um agenciamento coletivo.

Em suma, a literatura é devir porque se constitui numa linha de fuga para a qual vida e escrita se confundem, guiados por um impessoal. Esse impessoal é a deflagração do coletivo, eliminação do eu e, por isso, eliminação do que é subjetivo. Em síntese, a escrita não é interior, não se produz expressando uma história particular. Pessoas, animais, naturezas são agentes em agenciamentos organizados, são funções em agenciamentos, são ofícios, o escritor é um ofício. A escrita se desenvolve das partículas que vêm desses agenciamentos. O que o devir faz é capturar partículas de desvio desses elementos minoritários, que formam um coletivo no maior grau de povoação. $O$ fato de o agente não ser outro, fazer fronteira com outro, ter só afectos e desejos como causadores de movimento, é que produz um devir.

\section{CONSIDERAÇÕES FINAIS}

O presente artigo abordou a afirmação feita por Gilles Deleuze e Félix Guattari de que a literatura é um caso devir e que a linguagem produzida na escrita é um 
agenciamento coletivo de enunciação, no qual o escritor não consegue contar a história de si, mas de um coletivo.

Assim, pode-se concluir, afirmando que a relação entre a literatura e o devir se dá na medida em que pensamos na literatura como produtora de enunciados próprios e quando a imaginamos como política, em virtude de ela ser afetada por agenciamentos que vem de um fora para estabelecer ligação com o processo de escrita.

Outro ponto determinante que se soma à ideia da literatura como caso de devir, se encontra no fato de ela apresentar uma fuga semântica e agramatical. Assim, constitui-se como língua menor aquela que desarticula a língua dominante, que a insere em um processo de devir. A literatura menor, por sua vez, seria aquela produzida no seio de uma língua dominante, por uma minoria, que tende a operar todas essas desterritorializações no modo de expressão. Envolve uma linguagem política, não no sentido de protestar ou de reproduzir padrões, mas uma linguagem revolucionária que ocorre por potências, e que pode ser considerada um devir porque é uma escrita rizomática, produzida em meio a múltiplas relações e múltiplos agenciamentos.

\section{REFERÊNCIAS}

ABREU, Ovídio. Deleuze e a Arte: o caso da literatura. Lugar Comum - Estudos de Mídia, Cultura e Democracia. Rio de Janeiro: Universidade Federal do Rio de Janeiro - UFRJ. Laboratório Território e Comunicação - LABTeC/ESS/UFRJ - Vol. 1, n. 23-24, pp. 199-209, 2006. Disponível em: http://uninomade.net/wpcontent/files_mf/110810121116Deleuze\%20e\%20a\%20Arte\%20\%200\%20caso\%20da\%20literatura\%20-\%200v\%C3\%ADdio\%20Abreu\%20.pdf Acesso em 24/09/2020.

BIRMAN, Joel. O signo e seus excessos: a clínica em Deleuze. In: Gilles Deleuze: uma vida filosófica. ALLIEZ, Éric (Org.). Coordenação da tradução de Ana Lúcia de Oliveira. - São Paulo: Ed. 34, 2000, coleção TRANS, 557 p. 
BLANCHOT, Maurice. O livro por vir. São Paulo: Martins Fontes, 2005.

DELEUZE, Gilles. Crítica e Clínica. Tradução de Peter Pál Pelbart; São Paulo: Ed. 34, 2011.

DELEUZE, Gilles; GUATTARI, Félix. 20 de novembro de 1923 - Postulados da lingüística. In: DELEUZE, Gilles; GUATTARI, Félix. Mil Platôs: capitalismo e esquizofrenia. Vol. 2, Tradução de Ana Lúcia de Oliveira e Lúcia Cláudia Leão. - São Paulo: Editora 34, 2012. 2. ed. Coleção TRANS, 557 p.

. Devir-intenso, Devir-animal, Devir-imperceptível. In: DELEUZE, Gilles; GUATTARI, Félix. Mil Platôs: capitalismo e esquizofrenia. Vol. 4, Tradução de Suely Rolnik. - São Paulo: Editora 34, 2012. 2. ed. Coleção TRANS, 557 p.

DELEUZE, Gilles; GUATTARI, Félix. Kafka. Por Uma Literatura Menor. Tradução e prefácio de Rafael Godinho; Lisboa: Assírio \& Alvim, 2002.

DELEUZE, Gilles; PARNET, Claire. Diálogos. Trad. Eloisa Araújo Ribeiro, São Paulo: Escuta, 1998.

DOSSE, François. Gilles Deleuze e Felix Guattari: Biografia Cruzada; Tradução de Fátima Murad; revisão Técnica de Maria Carolina dos Santos Rocha. - Porto Alegre: Artmed, 2010. 440 p.

MACHADO, Roberto. Deleuze: A Arte e a Filosofia. — Rio de Janeiro: Jorge Zahar Ed. 2009.

MELVILLE, H. Moby Dick: ou a baleia. São Paulo: Cosac Naif, 2013.

Bartleby, o escriturário; tradução de Cássia Zanon. - Porto Alegre: L\&PM, 2017.

PARNET, Claire. O abecedário de Deleuze. Título original: L'abécédaire de Gilles Deleuze. Direção; Pierre-André Boutang. França: Tv arte, 1994. 
SCHÉRER, René. Homo tantum: o impessoal uma política. Tradução de Paulo Nunes. In: Gilles Deleuze: uma vida filosófica. ALLIEZ, Éric (Org.). Coordenação da tradução de Ana Lúcia de Oliveira. - São Paulo: Ed. 34, 2000, coleção TRANS, 557 p.

\section{APÊNDICE - REFERÊNCIAS DE NOTA DE RODAPÉ}

2. Henri Bergson, Spinoza, Michel Foucault, Gilbert Simondon, Nietzsche, Sigmund Freud, Carl Gustave Jung, Stéphane Mallarmé e Maurice Blanchot, são apenas alguns dos nomes que de certa forma influenciaram a visão que Deleuze e Guattari mantêm sobre o sujeito, sobre corpo e natureza, e a ligação entre agentes, linguagem e instituições de poder.

3. Foram utilizadas nas obras aqui referenciadas, o ano de publicação de suas edições em língua portuguesa.

4. Moby Dick (1851) é um romance do escritor norte americano Herman Melville e narra a história do Capitão Ahab, comandante de um navio baleeiro, intitulado de Pequod, que investe numa caçada irracional atrás de uma baleia branca, chamada Moby Dick.

5. Cf. "Bartleby, ou a fórmula", presente na obra Crítica e Clínica escrita por Gilles Deleuze.

6. "Preferiria não" (optou-se por utilizar a tradução que se encontra no livro Crítica e Clínica).

7. cf. PARNET, Claire. O abecedário de Deleuze. Título original: L'abécédaire de Gilles Deleuze. Direção; Pierre-André Boutang. França: Tv arte, 1994, p. 06.

Enviado: Janeiro, 2021.

Aprovado: Janeiro, 2021. 